\title{
Doctoral Students Living, Leading, and Learning During a Pandemic
}

\author{
Debra Bukko \\ CSU Stanislaus \\ dbukko@csustan.edu \\ Jaskaran Dhesi \\ CSU Stanislaus \\ jdhesi@csustan.edu
}

\begin{abstract}
Purpose: The purpose of this study was to understand the impact of COVID-19 on doctoral students' personal, professional, and academic roles and factors contributing to their persistence during the pandemic.

Research Methods: The researchers engaged in qualitative research at a California State University CPEDinspired Ed.D. program, using semi-structured interviews, document analysis and a focus group. Data were analyzed through the CPED mentoring and advising framework, transformative learning theory, and selfauthorship theory.

Results: Three themes emerged: a convergence of roles within home and virtual spaces, leading in a complex and uncertain time, and caring relationships encourage persistence.

Implications: Participants experienced increased self-awareness and development of cognitive, interpersonal, and intrapersonal dimensions of self. Relationships between cohort members and with faculty were integral to student persistence during a time of significant change and uncertainty. Recommendations for practice within Ed.D. programs and for future research are offered.
\end{abstract}

\section{KEYWORDS}

education doctorate, transformative learning, self-authorship, mentoring, cohort

Engaging in an educational leadership doctoral program is a significant undertaking. Accomplished working professionals experience knowledge construction and deconstruction as well as critical reflection and meaning making that may prompt them to question long-held beliefs and professional practices (Collay \& Cooper, 2008; Cunningham, 2018; Stevens-Long et al., 2012). This experience creates disorientation in the most stable contexts.

Instability emerged in March 2020 when California's governor and the state's public health officer issued the COVID-19 Stay at Home Order (Exec. Order No. N-33-20, 2020) mandating all Californians stay in their residences unless meeting essential needs or performing essential work. This created a dramatic change in how individuals live, work, and study.

As a result of COVID-19 and the California Stay at Home Order, Ed.D. scholars transitioned from face-to-face to virtual learning spaces. As professionals, they led educational communities through a similar transition, rapidly adapting policies and practices in unprecedented and uncertain circumstances. Further compounding the complexity, doctoral students became teachers as their children engaged in distance learning. Despite pervasive challenges created by the pandemic, students persisted in their pursuit of an education doctorate.

New articles in this journal are licensed under a Creative Commons Attribution 4.0 United States License.
The purpose of this study was to understand the ways doctoral students were impacted by and responded to the academic, professional, and personal challenges created by the COVID-19 pandemic. We also sought to understand experiences influential to their academic persistence.

\section{LITERATURE REVIEW}

Doctoral studies provide rich opportunities for knowledge creation, critical reflection, self-awareness, and social capital development for working professionals. In Ed.D. programs, scholarpractitioners learn about foundations of education, policies, and practices to challenge and transform those foundations and to use research to understand and to innovate in complex educational institutions (Burnard et al., 2018; CPED, 2020; Perry, 2015; Wergin, 2011). A professional doctorate in education facilitates knowledge acquisition and development of the "habits of hand, heart and mind" (Perry, 2015, p. 59) needed to transform educational practice.

In Ed.D. programs, scholars experience disorienting dilemmas and transformative learning (Collay \& Cooper, 2008; Cunningham, 2018) as they develop cognitive, interpersonal, and intrapersonal

This journal is supported by the Carnegie Project on the Education Doctorate: A Knowledge Forum on the EdD (CPED) cpedinitiative.org 
dimensions of self (Baxter Magolda, 2008). Throughout the process, scholar-practitioners build on their knowledge and lived experiences, co-create knowledge with others, and lead to improve educational experiences and outcomes in their institutions (Buss et al, 2017; George, 2017; Perry, 2015; Porfilio et al., 2019).

This integration of scholarship and practice is supported by the Carnegie Project for the Education Doctorate (CPED) and is recommended by Wergin and Alexandre (2016) who argue for doctoral programs that promote collaborative integration of professional expertise, organizational rather than individual excellence, and a focus on problem-solving rather than conflict avoidance. An integrated approach requires an Ed.D. program structure designed to both challenge and support students (CPED, 2020; Pratt et al., 2015; Wergin \& Alexandre, 2016). Support systems include a cohort model and mentoring that honors student and faculty knowledge and experience (CPED, 2020; Perry, 2015).

A review of literature related to Ed.D. program components is synthesized into subsections examining leadership identity development, agency in learning and leadership, pedagogy, a cohort model structure, and mentoring. The literature review concludes with subsections on the theoretical frameworks of transformative learning and self-authorship.

\section{Leaders in Learning Communities}

As working professionals, Ed.D. students are leaders who may not have conceptualized their identities as researchers and scholars (Chapman, 2017; Hall \& Burns, 2009). Central to the professional doctorate experience is a "pedagogic model that infuses theory with practice and supports students' intellectual and professional development as reflective learners, practitioners, and scholars" (Wergin \& Alexandre, 2016, p. 235). Unlike graduate programs in which faculty knowledge is prioritized over that of students, this model features an intentional and integrated focus on shared learning, critical reflection, and examination of assumptions (Perry, 2015; Pratt et al., 2015; Scott et al., 2004; Wergin \& Alexandre, 2016). Knowledge and skill development is framed in environments characterized by situated learning (Brown et al., 1989) in which habits of mind are developed within a community of practice (Baxter Magolda, 2009; Cranton, 2016; Pratt et al., 2015).

These learning communities include active and inquiry-based learner-centered experiences in which students engage in knowledge acquisition and application in real-world contexts (Perry, 2015; Scott et al., 2004). Such inquiry-based shared learning takes place within student cohorts and creates opportunities for agentic development as learning experiences intersect academic, personal, and professional spaces (Pratt et al., 2015). The learning impact extends beyond professional practice and into an individual's sense of self and relationships with others (Scott et al., 2004; Webber, 2017; Wellington \& Sikes, 2006).

\section{Agentic Development}

Critical reflection and examination of assumptions and beliefs during the Ed.D. journey impact students' sense of self (Burnard et al., 2018; Scott et al., 2004; Webber, 2017; Wellington \& Sikes, 2006). Individuals' professional and personal identities may be challenged and transformed as they construct knowledge of educational concepts and theories and become critically aware of perceptions of self and others (Pratt et al., 2015; Scott et al., 2004).
Recognizing that identity "constantly evolves in the face of the everchanging challenges with which we are presented" (Cunningham, 2018 , p. 67), intentional use of pedagogy to shape students' evolving selves is important (Baxter Magolda, 2009; Pratt et al., 2015).

Learning experiences that promote examination of personal beliefs and professional practices may cause tension for some individuals (Baxter Magolda, 2008; Burnard et al., 2018; Cranton, 2016; Mezirow, 2000; Webber, 2017). A pedagogy utilizing dimensions of both transformative learning theory (Cranton, 2016; Mezirow, 2000) and self-authorship theory (Baxter Magolda, 2008) may create disorienting dilemmas that place students at a crossroads in their thinking and sense of self as leaders and learners. Pedagogical design, shared learning through a cohort model, and mentoring and advising are three Ed.D. program components which serve to facilitate the transformation from leader to scholar-practitioner (CPED, 2020).

\section{Pedagogy}

Pedagogical approaches that engage students in development of a sense of community and belonging and that foster connections between program learning and professional practice support agentic development (Burnard et al., 2018; Pratt et al., 2015; Scott et al., 2004; Webber, 2017). A pedagogy that facilitates development of a "coherent identity" (Baxter Magolda, 2008, p. 269) supports individuals in facing challenges with confidence they can make decisions and take action in ways that capitalize on their capacity to think critically, collaborate productively, and balance competing demands in their personal and professional lives (Baxter Magolda, 2009). Through such a pedagogical approach, individuals develop their capacity to recognize multiple perspectives, balance internal and external forces on thinking and meaning making, and clarify their leadership philosophy (Collay \& Cooper, 2008).

\section{Cohort Model}

The cohort model provides Ed.D. scholars a community of practice that may reduce feelings of isolation while also facilitating cognitive development through co-constructing knowledge with others (Klenowski et al., 2011; Wenger, 1998). As a social construct, the cohort model provides a framework which fosters interdependence and upon which pedagogical practices engage students in developing meaning, community, practice, and identity (Collay \& Cooper, 2008; Wenger, 1998). In this model students develop a sense of self as both unique individuals but also a member of an interdependent community that extends beyond doctoral program coursework. Students' academic, personal, and professional learning are dynamic and relational and members support one another through shared understanding, insight, advice and problem-solving (Klenowski et al., 2011; Wenger, 1998). Support within a cohort is augmented through mentoring.

\section{Mentoring}

Literature documents the importance of mentoring in graduate education, especially for first generation and students of color (Brunsma, et al., 2017; Bukko et al., 2019; Rudolph, et al., 2015; Sedlacek et al., 2007). Mentoring in CPED inspired programs is reciprocal with both student and mentor bringing expertise and knowledge to the relationship (Perry, 2015). The CPED mentoring framework is one built on the premise that responsive and mutually 
respectful mentoring fosters dynamic learning and individual development. Inclusive of peer support and provided by multiple rather than assigned faculty, mentoring is flexible and responsive to individuals' unique needs and circumstances (CPED, 2020). This model may counter the disorientation created during transformative learning experiences.

\section{Transformative Learning}

Transformative experiences create dissonance as students become increasingly aware of socio-cultural realities, their own beliefs and assumptions, and their capacity as scholar-practitioners to lead change in educational institutions (Cranton, 2016; Mezirow, 2000). "Transformative learning shapes people. Individuals experiencing transformation are different afterward, in ways both they and others can recognize" (Clark, 1993, p. 47). Learning to understand and to act on our own knowledge and beliefs rather than to follow those "uncritically assimilated from others" (Mezirow, 2000, p. 8) is imperative in this transformation. Faculty awareness of students "at the edge of their knowing" (Taylor, 2007, p. 183) fosters critical reflection, dialogue, and engagement among knowledge coconstructors. During such learning experiences students construct epistemological knowledge regarding how they view the world, interpersonal knowledge in how they view relationships with others, and intrapersonal knowledge, becoming more deeply aware of how they view themselves (Cranton, 2016; Kegan, 1994; Mezirow, 2000). These three dimensions are integral to students' self-authorship.

\section{Self-Authorship}

Baxter Magolda (2009) identified the connection between transformative learning and self-authorship based on a 22-year longitudinal study investigating adult learning and development. Three themes emerged from this study: trusting the internal voice (how they react to realities), building an internal foundation (purpose and beliefs that inform reactions), and securing internal commitments (living their internal foundation). Baxter Magolda (2009) found that "transformative learning required a shift from uncritical acceptance of external authority to critical analysis grounded in internal authority" (p. 2). When engaged in a disorienting dilemma, individuals find themselves at a crossroads or in transition moments during which they may struggle to reconcile their internal beliefs with external voices (Baxter Magolda, 2008; Kegan, 1994). Those who navigate these transitions in ways that challenge dependence on authority and "coordinate, integrate, act upon, or invent internal values, beliefs, and convictions" (Kegan, 1994, p. 185) achieve a sense of personal authority Kegan (1994) termed self-authorship.

The CPED mentoring framework, transformative learning theory (Cranton, 2016; Mezirow, 2000) and self-authorship theory (Baxter Magolda, 2008, 2009) guided development of this empirical research and provided frames through which data were analyzed and interpreted.

\section{RESEARCH METHODS}

\section{Context}

The Ed.D. program at Central University (pseudonym) is a three-year, cohort-based, face-to-face program. Graduates describe their doctoral experience as a time of rigorous learning and high levels of personalized faculty, staff, and fellow student support (Bukko et al., 2019). Students are P-20 working professionals who engage in foundational coursework in year one, P-12 and community college/higher education specialization courses in year two, and capstone/dissertation research in year three. To date, 121 students in ten cohorts have completed the doctoral degree and are serving as $\mathrm{P}-20$ educational leaders throughout the region.

In March of 2020, the program pivoted from in-person to synchronous virtual classes using Zoom. Faculty and students adapted processes and program events with a focus on maintaining the interactive and face-to-face nature of coursework, mentoring, and socialization events using the Zoom platform.

During the summer term, participants completed a year two specialization course, their Written Qualifying Examination, and began the literature review for their capstone/dissertation research. During data collection, students were enrolled in a fall course and worked independently with their dissertation chair to further develop the literature review.

With a focus on the disorienting dilemma of the COVID-19 pandemic, the researchers sought to understand the COVID-19 impact on students' academic, professional, and personal experiences and to explore the ways in which Ed.D. program components or experiences may have influenced their persistence in the doctoral program.

\section{Participants}

Qualitative research was used to gather the perspectives of Ed.D. students taking a penultimate year one course when the program pivoted to virtual spaces due to COVID-19. This methodology allowed for participant interpretation and attribution of meaning to their lived experiences (Merriam \& Tisdell, 2016).

All cohort members were invited to participate in the study, and the final sample included 10 participants, 7 of whom identify as female and three who identify as male. Participants describe themselves as identifying with one of 6 different ethnicities, half speak 2 or more languages, and 4 have lived in countries outside of the United States. Participant ages range from 34 to 46 and 8 are parents of school age children; in addition, 4 provide financial and emotional support for parents and extended family. Half of the participants are first generation students with neither parent or guardian completing a community college or four-year degree. Participants are all working professionals, serving in P-20 educational institutions as teachers, counselors/advisors, administrators, and staff.

\section{Data Collection}

Primary data were collected through semi-structured interviews via Zoom. Interviews included open and indirect questions which prompted students to share their academic, professional, and personal experiences before and after the advent of COVID-19 (Merriam \& Tisdell, 2016). Participants were also asked questions which generated descriptions of challenges and points of celebration related to their courses, with cohort members, with faculty, and as individuals in their professional and personal contexts.

Secondary data were drawn from the students' Written Qualifying Examination (WQE) submissions. The WQE was assigned before the advent of COVID-19 and serves as a program 
assessment to determine students' readiness for advancement to candidacy. In addition, the prompt was designed to assess program effectiveness and areas for growth. The WQE includes one part in which students reflect upon their experience and development as scholar-practitioners. Through exploration of theories, concepts, and development of habits of mind during their first year in the Ed.D. program, students were asked to respond specifically to the question, "What type of scholar-practitioner am I becoming through my participation in the Ed.D. program?" Students submitted their written reflections before the semi-structured interviews were conducted.

Data from the interviews and written reflections were then analyzed and initial findings were developed. Initial findings were presented to participants in a focus group session. The three data sources, interviews, document analysis, and focus group, allowed for triangulation, member checking, further theme exploration, and served as a resource to corroborate or refute initial findings (Merriam \& Tisdell, 2016).

\section{Data Analysis}

Researchers engaged in reflexivity and collaborative coding throughout data collection and analysis, individually and collaboratively articulating and examining assumptions and dispositions regarding the research and interpretations (Miles et al., 2019). To look for data that may support alternate findings and to reduce bias impact, a researcher familiar with the topic and who works outside of the Ed.D. program provided peer examination of raw data and assessed plausibility of findings (Merriam \& Tisdell, 2016).

Data collected during semi-structured interviews were analyzed through thematic analysis and open coding (Braun \& Clarke, 2006), using the CPED mentoring framework, transformative learning theory (Cranton, 2016; Mezirow, 2000) and self-authorship (Baxter Magolda, 2008). Written Qualifying Examination (WQE) selfreflections were analyzed for latent and manifest meaning using document and thematic analysis (Bowen, 2009) as well as codes derived from interview analysis, open coding, and the lenses of selfauthorship and transformative learning. To ensure internal validity, excerpts that best exemplified each theme were selected and presented to participants in a focus group to provide respondent validation (Merriam \& Tisdell, 2016).

\section{FINDINGS}

Three themes emerged during this study: a convergence of individual, professional, and academic roles within home and virtual spaces, leading in a complex and uncertain time, and relationships encourage persistence.

\section{Theme 1: Living, Working, and Learning from Home}

The disorienting convergence of previously distinct roles into one lived space emerged as a significant impact for every participant. Within one week, participants pivoted to working and learning from home. Even though these accomplished working professionals possessed knowledge developed from life, work, and graduate level learning, their new reality challenged perceptions of themselves, their work, and their doctoral studies. This was captured clearly by one participant who shared:

I think of myself as very linear. I do this, then I do this, then I do this and this will get me this. So that hasn't changed because there's still an end goal of what this doctorate program is. But the value of the program has changed, the value of my life, the value of my relationships, the value of my stress level. Everything is just so new and unprecedented and not normal. Every day is different and just sort of feels like the world is crumbling and there's just scary things happening all the time.

This disorientation emerged in three sub themes related to living and working in a single space, energy and focus, and silver linings.

\section{All Aspects of Life in One Space}

Before COVID-19, participants indicated life was more compartmentalized; after, they struggled to differentiate the parts of their lives as they became accustomed to living, working, and learning in one space. While their days and roles were previously defined by distinct home, work, and school spaces, many noted that home has now become the space for "all things in my life". One individual illustrated this when sharing:

I've always been pretty good about separating. In terms of, okay, now I'm at work and when I'm at work, I'm focused on work. And now I'm at school, I'm going to focus on school. Come home and focus on the kids. But now, it's kind of all convoluted because I'll have my son in one room doing school online, I'll have myself working on Zoom and then I've got my own studies, all kinds of things, just kind of going on simultaneously.

Working, studying, and living in the same space with family created feelings of being "overwhelmed", particularly for those with children. "I feel I have to be with them since I am home. Before [COVID-19] I was a mom when I was home and an employee at work. Now I am both at the same time, in the same place."

While participants at first believed this role convergence would be short term, the number of COVID-19 cases continued to climb. Six months after the Stay at Home Order, participants realized what they thought would be a short-term situation has become a long-term reality:

We're learning every day that it seems this is a long-term thing. At first I felt like I was going to be okay with this because it would only last for a little bit. And now it feels like, no, this is becoming the norm. And so you have to totally readjust how you organize yourself in all parts of your life.

The role convergence and the reality of living, working, and learning during a pandemic directly impacted participants' physical, mental, and emotional capacity.

\section{Energy and Focus: Compounded Stress and Deprivation}

The pandemic impact made it difficult for participants to maintain energy and focus. While none had tested positive for COVID-19, some struggled with health concerns requiring medical intervention. Navigating the health care system during a pandemic was challenging and also created fear of contracting COVID-19 as they sought treatment. It also created anxiety and uncertainty about their future in the doctoral program:

When I had a health scare I thought, this is it. I will have to quit this program. I won't be able to finish it, and I really want to finish it. 
But I said, is it worth it to push myself and focus on that? Then the family and my partner's lost job ... I mean, all of this I was going through, and it was just ... just so much.

Physical health concerns were compounded for those faced with economic impact as they or their partners experienced job loss. This economic uncertainty emerged as a stressor for several participants as budget cuts and organizational changes make them question employment stability.

In addition to the health and economic impact, participants also expressed feelings of deprivation due to not being able to see family, friends, coworkers, and fellow doctoral students. Celebrations were cancelled and restrictions on outdoor experiences created feelings of being "trapped" in their homes. This resulted in lost energy and focus in their professional and academic work. One participant shared, "I found myself saying, I know I'm supposed to be working on this, but I just can't right now". Every participant shared this stress which was magnified by the pain experienced by others.

\section{Emotional Labor}

Participants identified two sources of emotional labor. The first emerged in their work context. These leaders listened to teachers, students, and colleagues express frustrations and personal challenges. One participant articulated a reality echoed by others when explaining:

I hear a lot of stress from everyone. And sometimes when they tell me what they're going through, and their parents being sick, and their family members dying because of COVID, and that they can't teach online or help their kids and work, it's really stressful on me too because I feel like I need to be there for them. At some point, some days I was like, I just can't today. I just can't because it's just too much. I need a mental break.

Several participants described this emotional labor as traumatic and impacting their ability to sleep, to focus, and to interact with others.

A second source of emotional labor arose from the rapidly changing circumstances in participants' professional lives. Leaders were challenged to create and then recreate new policies and practices as circumstances evolved:

It is exhausting to create and recreate over and over. What made me more exhausted is the emotional weight of that. Because you know you're responsible for thousands of students and making sure that they're taken care of. So, every decision you make, you're weighing the welfare of the community and it's heavy. It's exhausting.

Every participant described the physical and emotional exhaustion experienced as they worked extended hours in challenging circumstances to respond to "the world being turned upside down." This created disequilibrium that further contributed to stress and feelings of deprivation.

\section{Feeling out of Balance}

Increased emotional labor and limitations on physical activities created a feeling of lost balance in the physical, mental, and social aspects of life. Those who previously would have restored energy by hiking, shopping, and going to lunch with friends no longer had those outlets. One participant described the reality experienced by many:

Each role, student, professional, parent, spouse, all of that has been changed because of COVID. Just the fact that you don't get to leave the house. I mean, my family doesn't leave. My kids are at home all day on Zoom doing distance learning. My wife is teaching from home. So, I get home at the end of the day and I have three people looking at me like, oh good, someone else is here to entertain us because we're bored to tears. So, there is a need to take care of them socially and emotionally instead of taking care of myself.

During the pandemic, participants recognized practices they valued but had taken for granted before the shift to working from home. "I'm realizing I lost things I really enjoy that I didn't even realize I lost at first like the little cognitive and physical breaks to move from a meeting on one part of campus to another."

Participants' feelings of isolation and deprivation as an impact of the COVID-19 Stay at Home restriction was exacerbated by the shift to virtual platforms and the "Zoom fatigue of one meeting after another". Self-awareness of the deprivation they attribute to both emotional labor and the restricted engagement with others manifested in a commitment to self-care.

\section{Self-Awareness and Commitment to Self-Care}

The COVID-19 impact created physical and emotional challenges. Participants' responses to these challenges revealed increased awareness of and commitment to physical and mental health needs.

Self-Awareness. Several participants reported exhaustion, anxiety, and insomnia that prompted physician or therapist visits. One participant shared the realization, "that I am trying to squeeze all three roles into an eight-hour day, which is physically impossible." Another realized the importance of staying connected with friends. While social interactions occurred spontaneously when they were able to work or study on campus, several articulated the need to be purposeful in reaching out to friends: "I realized it's harder to connect with people. I have to really make it a focus of mine to say, 'Okay, right now I'm going to spend 20 minutes and I'm going to call a friend."”

In addition to intentional efforts to create positive connections, several participants explained they have reduced exposure to social and news media to protect their mental and emotional health:

I would hear the news and it would make me so mad. I've just realized recently that it's okay for me to step away from that, to not hear that and to choose what I allow to invade my mind. I think it's good to be educated and knowledgeable about what's going on and you just don't want to live in your own little bubble, but there's also something powerful about saying, "Not right now," or, "I don't need that. This is enough."

Every participant discussed realizations they need to find balance and that mental energy is limited and needs restoration. Their increased self-awareness resulted in participants taking steps to control their exposure and response to stress.

Commitment to Self-Care. Several participants recognized the importance of "reminding myself to take care of me. A lot of us want to take care of our students because they come first. But if you can't help yourself, you can't help the students." They also recognized the need to eat well and to exercise regularly, committing to daily walking, meditation, or yoga. They are striving to "balance it all even though COVID has made it tough." Recognizing the 
importance of self-awareness and self-care has helped participants to identify positives within the turmoil.

\section{Silver Linings}

Although participants identified challenges emerging from COVID-19, they also identified positive impacts of their changed circumstances. In terms of self and family, they recognize the privilege of working from home and reducing family exposure to COVID-19. They also valued "savings" and "extra time" previously spent commuting to work and class. Most notably, participants identified the potential for meaningful educational reform:

This long-term disaster gives us the opportunity to make changes we've always needed to make to close the gaps between the haves and the have nots, to fix so much of what's wrong in our system. Normal is gone. No more excuses. We have to change.

Citing educational reform as a motivation for pursuing a doctorate, participants recognized both the challenges and the opportunities emerging from the COVID-19 impact. While they value this rare opportunity for sweeping reform, they also recognize the challenge of educational leadership in an uncertain time.

\section{Theme 2: Leadership in a New Normal}

Leadership in their professional contexts during COVID-19 was described as mentally and physically exhausting. This was attributed to the rapid shift from in person to virtual educational services and adaptation of leadership practices. Throughout this process, participants reflected on leadership complexity and their evolving leadership identity as they connected Ed.D. program learning to problems of practice in their professional context.

\section{Rapid Changes in a Complex System}

The most significant challenge in participants' professional lives was the need to "blow everything up and rebuild it without hurting people". This complexity was illustrated through an analogy: "when a machine breaks, you just have to replace or fix the part that is broken. We are inventing a new machine and the parts are human beings".

Participants recognized "the nature of organizational life is changing at every level" and described the need for examining and revising policies and practices. They were tasked with safely providing meals and basic services to school dependent students, shifting from paper to electronic document processing, providing technology and support for employees to work remotely, and helping faculty as they learned to teach both synchronously and asynchronously. "There is no part of my job that has been untouched" was a common refrain.

As participants pivoted in their professional practice, they recognized the "changing nature of our work as leaders" and realized the ongoing impact of COVID-19 requires a "whole different type of leadership to help others stay motivated and engaged in this important work". Participants explained that six months after the initial impact, the need for adaptive leadership continues because "this COVID reality changes hour by hour, then day by day, week by week. Next week we may be back to day by day. We have to be ready for anything." Being in a state of constant change, participants realized an evolution in leadership understanding and practice.

\section{Evolving Leadership Practices}

While feeling overwhelmed continues for many, participants recognize they "continue to bounce back and adapt" as leaders. Several acknowledged that while before COVID-19 they could "walk down the hall and check in with staff" they must now be intentional in when and how they interact with those they lead. Leaders recognized that "Building trust is more important than ever before" and realize how they communicate and interact during unstable times, "sets the tone others will build upon."

Participants articulated the need to resist a default reaction to "add more" and instead lead others through reconceptualizing the work they are doing with student needs at the center of decision making. This common feeling was illustrated by one participant who shared:

Knowing that students tend to come from lower socio-economic backgrounds, I consider how they are affected by issues with internet or wifi access, housing or lack of, crowded homes, lack of basic needs, and mental health. These factors have to be considered when thinking about all services, including grading practices, financial aid, assigning work, accessing Zoom, and supporting them emotionally and academically.

Aware of the "threat of deficit thinking to creating equity", participants argued that COVID-19 "made so many oppressive systems apparent". Balancing student needs, those of faculty and staff, and their own mental and physical exhaustion, participants recognized the importance of staying flexible yet also true to their individual motivations and leadership philosophies. They consistently identified a need to understand themselves as vital to being an effective leader.

\section{Connecting Leadership and Learning}

As leaders during rapid and complex change, these scholarpractitioners described an evolving sense of self and leadership identity. All participants cited reforming educational systems as integral to their leadership sense of purpose. One described a sentiment expressed by all as, "My end goal is to be an effective leader who collaborates to create unique solutions that help students acquire and internalize knowledge as empowered individuals." Participants recognize deficit thinking and are "passionate about developing educational systems that are designed to uplift and not oppress." They referenced specific program learning and their development of a deeper understanding of what it means to be a scholar-practitioner to achieve their leadership goals. One participant expressed this understanding as, "being attuned to new knowledge that is being constructed and using it to be an agent of change."

Across all data sources, participants revealed critical reflection as central to understanding the ways their leadership practices and self-perception have evolved. They cited self-reflection as integral to "understanding oneself and evolving in my habits of mind." Many attributed positive changes to post COVID-19 connections made between workplace challenges, Ed.D. program learning, and the support they receive from peers and faculty.

\section{Theme 3: Relationships Encourage Persistence}

The challenges posed by the impact of COVID-19 on educational leaders have been significant with ripple effects extending into personal and professional lives. Despite this, participants persist in their doctoral studies, successfully completing 
year one coursework, the Written Qualifying Examination, and initial work on the capstone/dissertation literature review. Examination of possible reasons for this persistence revealed the importance of relationships and support as Ed.D. candidates develop their scholar identity.

\section{Same but Different}

When asked to describe their Ed.D. program experience before the advent of COVID-19, participants most often used the terms engaging, rigorous, intellectually stimulating, and communal. They indicated appreciation for the "safe place to engage in critical conversations" as one motivator for taking on the challenge of pursuing doctoral studies. One participant described class sessions and program faculty as, "where I find my people, the people who see the need for change like I do yet we also challenge one another in how we see the world."

Participants indicated these descriptors remained consistent in the COVID-19 reality, explaining that "by shifting to synchronous Zoom classes, we still have a safe place to learn and engage in real time." They also described changes in their program experience, including a need for more self-reflection, increased comradery with cohort members, and feeling listened to and supported. While participants described being overwhelmed at times and that the level of academic expectations remained high, they also cited the support and the opportunity to explore a challenging experience with other leaders as a reason for continuing their studies.

\section{All for One and One for All}

A shared disorienting experience with increased support was identified as integral to participants' commitment to continuing their pursuit of a doctoral degree. Participants shared that when they questioned whether they should continue in the program, peer and faculty encouragement gave them "resolve", describing connections with the program as a safe haven: "This program is providing a safe space where I'm home with a nurturing family", "I'm learning and I'm growing", and "I think in a way the pandemic created space to learn and grow." Strengthened connections among students and between students and faculty have emerged despite the shift from in person to learning from home.

\section{Cohort Community}

Increased collaborative connections outside of class sessions was identified by participants as a source of "motivation, support, and a desire to learn from one another." Describing their cohort peers as individuals who "genuinely care about each other" and "people who won't let me give up", participants articulated a synergy that arises from the fact that "we all come from different walks of life; we add so much to one another". Feeling safe being vulnerable removed barriers when students struggled to make sense of their reading, to solve a professional problem, and to write when they were exhausted. One participant attributed her growth as a thinker, letting go of the fear of others seeing her struggle: "I feel safe saying, "Okay, what does that mean? What are we supposed to do? I don't understand this. Help now." Another shared:

We have informal Zoom sessions regularly. We'll come in and we'll just kind of commiserate, how are you doing, what are you struggling with, this and that? It's anything, non-program related, program related. And then we say, okay, we're going to work on this, work on whatever you want to work on for an hour. And we'll check back in, in an hour. It's giving that focused time to really, truly connect.

Multiple participants described these shared times as "healing" and "encouraging". Several indicated, "I can't quit. It would let my peers down and we've done so much to support one another in this crazy time." This sense of shared responsibility and support extended beyond the student to student relationship to that of student and faculty.

\section{Faculty Commitment and Care}

When asked to describe relationships with faculty before and after COVID-19, all participants indicated the level of care and commitment for student learning and persistence was high before COVID-19 and had increased afterward. They describe their program experience as "humanistic", "nurturing, "focused on high expectations", and inclusive of "personalized support".

While students were at first concerned with what would happen during a shift to remote learning, they consistently agree that faculty have "risen to the challenge" and maintained the interactive learning environment during class sessions. In addition to learning and leveraging technology tools, faculty have actively solicited input and have asked, "what do you need" and adapted learning activities to include that input. Faculty also "recognized the real problem of Zoom fatigue" and created learning activities that also include "screen breaks" and "found different ways for us to engage". In addition, participants expressed appreciation for faculty acknowledgement of the "learning from home" reality:

I love it when professors have reminded everyone that there's kids in the background because I have had craziness with kids and childcare. I am so thankful that professors don't mind seeing kids because my daughter was crying once and then later she was on screen making funny faces.

Participants expressed that while faculty and students are no longer meeting in a physical space, the commitment to maintaining the rigor and relevance of learning has remained constant. Prevalent in the data was a belief that faculty understand the challenges students are experiencing and are committed to supporting them.

In addition to being responsive to students' learning needs, participants shared an appreciation for the level of care faculty extend. Examples include faculty members regularly sharing messages of encouragement via email, text messages, and phone calls. One participant shared, "they see we are human, and we need support to stay in the program." Others noted the rapid response students receive to questions and requests for help. "The fast responses are even more important now because everything is so uncertain. I feel like I am important to them, even when they are impacted by all of this, too." A personal connection and continuous message of belief in and support for students was cited as instrumental in their decision to continue in their pursuit of a doctoral degree.

\section{DISCUSSION}

The novel coronavirus impacts health and societal systems (Dubey et al., 2020; Exec. Order No. N-33-20, 2020; Horesh \& Brown, 2020; Nicola et al., 2020; Qiu et al., 2020). The disorientation of living, working, and learning from home creates psycho-social impact that early studies indicate may adversely impact physical and 
psychological well-being (Dubey et al., 2020; Horesh \& Brown, 2020; Qiu et al., 2020). These impacts were evidenced in this study examining the COVID-19 impact on students in an educational leadership doctoral program.

Findings indicate participants were challenged by the convergence of their personal, professional, and academic roles into one lived space. This created stress, feelings of deprivation, and emotional labor as scholar-practitioners endeavored to meet professional challenges, maintain their scholarship, and care for families and themselves. Learning to lead and develop their scholarpractitioner identity in unprecedented circumstances provided disorienting crossroads moments. Ed.D. program learning and support from cohort members and faculty contributed to increased confidence and commitment to their profession and to their pursuit of the doctorate. Analysis of these findings reveal an intersection of transformative learning, self-authorship, and mentorship as integral to participants' reactions to the disorientation caused by the COVID19 impact and to their persistence in the doctoral program.

The disorienting shift from distinct to converged roles created a crossroads moment. They experienced transformative learning as individuals, scholars, and leaders as they struggled to find balance, to construct meaning in unprecedented and uncertain circumstances, and to critically reflect upon their assumptions and actions as scholar-practitioners (Cranton, 2016; Mezirow, 2000).

Cognitively, they drew upon funds of knowledge developed from lived experiences in their personal and professional contexts as well as their doctoral program learning (Baxter Magolda, 2008). They critically assessed and reflected on their habits of mind (Cranton, 2016) and engaged in meaning making (Baxter Magolda, 2008) as they created and recreated educational systems and practices in response to the "new normal" of distance learning. Drawing on support from faculty and cohort mentors, participants mutually engaged in shared learning and sought critical feedback as they worked to meet rigorous academic standards and to understand and resolve professional problems of practice (CPED, 2020).

Interpersonally, participants engaged with cohort members and faculty, seeking diverse perspectives as they worked to understand their knowledge and internal beliefs in response to external demands (Baxter Magolda, 2008; Cranton, 2016; Mezirow, 2000). While some briefly considered dropping out of the doctoral program, they persisted, relying on authentic relationships and critical friendships with others to fuel their commitment to the profession, themselves, and their academic endeavors (CPED, 2020).

Intrapersonally, scholar-practitioners attained a deeper understanding of self. They recognized the negative impact of COVID-19 conditions to their emotional and physical health and drew upon internal foundations to enact agency by reducing exposure to stress and increasing attention to self-care. This agency and internal sense of self helped them to regulate and interpret reactions to experiences and external forces (Baxter Magolda, 2008).

Participants attributed growth in self-perception to the safe and supportive learning environment during classes and in relationships with faculty and cohort members (CPED, 2020).

COVID-19 created an immediate impact on the lived cognitive, intrapersonal, and interpersonal experiences of participants in this study. The ripple effects of this impact revealed Ed.D. program components which students identified as factors that supported their persistence in the program. The following recommendations are centered in the students' identification of transformative pedagogy, a student-centered environment characterized by rigor with care and support, and multi-faceted mentoring as Ed.D. program components that foster persistence.

\section{RECOMMENDATIONS FOR PRACTICE IN ED.D PROGRAMS}

Webber (2017) contends "that the role of care is part of the academy's duty" (p. 163). Findings from this research support this contention, and we offer the following recommendations for fostering development of Ed.D. student agency and self-authorship.

Construct transformative learning experiences that place students at a crossroads in which they are prompted to question the nature of reality. Such pedagogical approaches challenge thinking and require critical reflection and critical self-assessment; this facilitates development of the cognitive dimension (Baxter Magolda, 2009; Pratt et al., 2015).

Support interpersonal development by creating mutually respectful and engaging environments in which students form critical friendships with one another and with faculty. Such environments validate a learner's capacity to know, situate learning in learners' experiences, and allow for mutual knowledge creation (Baxter Magolda, 1998, 2009; Cunningham, 2018; Pratt et al., 2015).

Develop systems that nurture mentoring relationships between students within a cohort model and encourage student mentoring relationships with multiple faculty members. Integrating mentoring throughout the Ed.D. program experience affirms the value of adult learners' perspectives and voices and creates opportunities for learning and understanding of individuals' unique crossroads moments (Baxter Magolda, 2009; CPED, 2020).

\section{RECOMMENDATION FOR RESEARCH}

This research provides insight into the unique experience of a cohort of doctoral students during a global health pandemic. Findings are limited by the small sample size, individual participant contexts, and the doctoral program in which they are enrolled. Additional research exploring the impact of COVID-19 on students in other Ed.D. programs would expand on what is known.

\section{REFERENCES}

Bukko, D., Cárdenas, J. \& Coletta, R. (2019). Ripple effects: Multifaceted mentoring of educational leadership doctoral students. Journal of Transformative Leadership \& Policy Studies, 8(1), 8-32).

Baxter Magolda, M. B. (2008). Three elements of self-authorship. Journal of College Student Development, 49(4), 269-284.

Baxter Magolda, M. B. (2009). Promoting self-authorship to promote liberal education, Journal of College and Character, 10(3). https://doi.org/10.2202/1940-1639.1079

Bowen, G. A. (2009). Document analysis as a qualitative research method. Qualitative Research Journal, 9(2), 27-40. https://doi.org/10.3316/QRJ0902027

Braun, V. \& Clarke, V. (2006). Using thematic analysis in psychology. Qualitative Research in Psychology, 3, 77-101.

Brown, J. S., Collins, A., \& Duguid, S. (1989). Situated cognition and the culture of learning. Educational Researcher, 18(1), 32-42.

Brunsma, D., Embrick, D., \& Shin, J. (2017). Graduate students of color: Race, racism, and mentoring in the white waters of academia. Sociology of Race and Ethnicity, 3(1), 1-13. 
Burnard, P., Dragovic, T., Ottewell, K., \& Lim, W. (2018). Voicing the professional doctorate and the researching professional's identity: Theorizing the EdD's uniqueness. London Review of Education, 16(1), 40-55.

Buss, R. R., Zambo, R., Zambo, D., Perry, J. A., \& Williams, T. R. (2017). Faculty members' responses to implementing re-envisioned EdD programs. Studies in Higher Education, 42(9), 1624-1640.

Chapman, A. (2017). Using the assessment process to overcome Imposter Syndrome in mature students. Journal of Further and Higher Education, (41)2, 112-119

Clark, M. C. (1993). Transformational learning. In S. Merriam (Ed.), An update on adult learning theory: New directions in adult and continuing education (No. 57, pp. 47-56). Jossey-Bass.

Collay, M., \& Cooper, J. (2008). Transformational learning and role of selfauthorship in developing women leaders. Journal of Research on Leadership Education, 3(2), 1-21.

CPED. (2020). The CPED Framework. The Carnegie Project on the Education Doctorate. Retrieved from: https://www.cpedinitiative.org/the-framework

Cranton, P. (2016). Understanding and promoting transformative learning (3rd ed.). Stylus Publishing

Cunningham, B. (2018). Pensive professionalism: The role of 'required reflection' on a professional doctorate. London Review of Education, 16(1), 63-64.

Dubey, S., Biswas, P., Ghosh, R., Chatterjee, S., Dubey, M., Chatterjee, S. Lahiri, D. \& Lavie, C. J. (2020). Psychosocial impact of COVID-19. Diabetes \& Metabolic Syndrome Clinical Research \& Reviews, 14(5), 779-788

Exec. Order No. N-33-20 (2020).

George, P. (2017). Toward a social justice model for an EdD program in higher education. Impacting Education: Journal on Transforming Professional Practice, 2(1), 41-52.

Hall, L. A., \& Burns, L. D. (2009). Identity development and mentoring in doctoral education. Harvard Educational Review, 79(1), 49-70.

Horesh, D., \& Brown, A. D. (2020). Traumatic stress in the age of COVID-19: A call to close critical gaps and adapt to new realities. Psychological Trauma, 12(4), 331-335.

Kegan, R. (1994). In over our heads: The mental demands of modern life. Harvard University Press.

Klenowski, V., Ehrich, L., Kapitzke, C., \& Trigger, K. (2011). Building support for learning within a doctor of education programme. Teaching in Higher Education, 16(6), 681-693.

https://doi.org/10.1080/13562517.2011.570431

Merriam, S., \& Tisdell, E. (2016). Qualitative research: A guide to design and implementation (4th ed.). Jossey-Bass.

Mezirow, J. (2000). Learning to think like an adult: Core concepts of transformation theory. In Mezirow, J. (Ed.). Learning as transformation: Critical perspectives on a theory in progress (pp. 3-33). Jossey-Bass Publishers.

Miles, M., Huberman, A., \& Saldaña, J. (2019). Qualitative data analysis: A methods sourcebook (4th ed.). Sage Publications.

Nicola M., Alsafi Z., Sohrabi C., Kerwan A., Al-Jabir A., losifidis C., Agha M., \& Agha R. (2020). The socio-economic implications of the coronavirus and COVID-19 pandemic: a review. Int. J. Surg. 2020;78:185-193. https://www.ncbi.nlm.nih.gov/pmc/articles/PMC7162753/\#

Perry, J. (2015). The Carnegie project on the education doctorate, Change: The Magazine of Higher Learning, 47(3), 56-61. https://doi.org/10.1080/00091383.2015.1040712

Porfilio, B. J., Strom, K., \& Lupinacci, J. (2019). Getting explicit about social justice in educational doctoral programs in the U.S.: Operationalizing an elusive construct in neoliberal times. The Journal of Educational Foundations, 32(1-4), 104-123.

Pratt, N., Tedder, M., Boyask, R., \& Kelly, P. (2015). Pedagogic relations and professional change: A sociocultural analysis of students' learning in a professional doctorate. Studies in Higher Education, 40, 43-59.

Qiu, J., Shen, B., Zhao, M., Wang, Z., Xie, B., \& Xu, Y. (2020). A nationwide survey of psychological distress among Chinese people in the COVID-19 epidemic: Implications and policy recommendations. General Psychiatry, 33, 2020;33:19-21. https://gpsych.bmj.com/content/33/2/e100213

Rudolph, B., Castillo, C., Garcia, V., Martinez, A., \& Navarro, F. (2015). Hispanic graduate students' mentoring themes: Gender roles in a bicultural context. Journal of Hispanic Higher Education, 14(3), 191-206.

Scott, D., Brown, A., Lunt, L., \& Thorne, L. (2004). Professional doctorates: Integrating professional and academic knowledge. Open University Press.

Sedlacek, W., Benjamin, E., Schlosser, L. \& Sheu, H. (2007). Mentoring in academia: Considerations for diverse populations. In T. Allen \& L. Eby (Eds.). The Blackwell handbook of mentoring (pp. 259-280). Blackwell Publishing.

Stevens-Long, J., Schapiro, S. A., \& McClintock, C. (2012). Passionate scholars. Adult Education Quarterly, 62(2), 180-198.

Taylor, E. W. (2007). An update of transformative learning theory: A critical review of the empirical research (1999-2005). International Journal of Lifelong Education, 26(2), 173-191.

Webber, L. (2017). Supporting professional doctorate women students through identity change and turbulent times: Who cares? Pastoral Care in Education: The Politics of Care, Compassion and Concern in the Contemporary Academy, 35(3), 152-165. https://doi.org/10.1080/02643944.2017.1363812

Wellington, J., \& Sikes, P. (2006). 'A doctorate in a tight compartment': Why do students choose a professional doctorate and what impact does it have on their personal and professional lives? Studies in Higher Education, 31(6), 723-734.

Wenger, E. 1998. Communities of practice: learning, meaning and identity. Cambridge University Press.

Wergin, J. (2011). Rebooting the EdD. Harvard Educational Review, 81(1), 119-140. https://doi.org/10.17763/haer.81.1.fp775268x77n0122

Wergin, J. \& Alexandre, L. (2016). Differentiation and integration: Managing the paradox in doctoral education. In Emerging Directions in Doctoral Education (Vol. 6, pp. 225-242). Emerald Group Publishing Limited. 